\title{
A introdução da explicação científica dos acontecimentos ambientais: focos de disputa entre o Setor Elétrico e os movimentos de Atingidos - Tucuruí, Pará
}

The introduction of scientific explanations of environmental phenomena: forms of conflict between the Hydroelectric company and affected social groups-

Tucuruí, Pará

\section{Rodica Weitzman}

\section{(2) OpenEdition}

\section{Journals}

Edição electrónica

URL: https://journals.openedition.org/aa/9309

DOI: $10.4000 / a a .9309$

ISSN: 2357-738X

\section{Editora}

Programa de Pós-Graduação em Antropologia Social (UnB)

Edição impressa

Paginação: 66-86

ISSN: 0102-4302

Refêrencia eletrónica

Rodica Weitzman, «A introdução da explicação científica dos acontecimentos ambientais: focos de disputa entre o Setor Elétrico e os movimentos de Atingidos - Tucuruí, Pará», Anuário Antropológico [Online], v.47 n.1 | 2022, posto online no dia 31 janeiro 2021, consultado o 23 julho 2022. URL: http:// journals.openedition.org/aa/9309; DOl: https://doi.org/10.4000/aa.9309

\section{c) (i) $\Theta$}

Creative Commons - Atribuição-NãoComercial-SemDerivações 4.0 Internacional - CC BY-NC-ND 4.0 https://creativecommons.org/licenses/by-nc-nd/4.0/ 


\section{A introdução da explicação científica dos acontecimentos ambientais: focos de disputa entre o Setor Elétrico e os movimentos de Atingidos - Tucuruí, Pará}

The introduction of scientific explanations of environmental phenomena:

forms of conflict between the Hydroelectric company and affected social groups - Tucurui, Pará

\section{Rodica Weitzman}

\section{OpenEdition}

Journals

\section{Edição electrônica}

URL: http://journals.openedition.org/aa/9309

DOI: $10.4000 /$ aa.9309

ISSN: 2357-738X

\section{Editora}

Programa de Pós-Graduação em Antropologia Social (UnB)

\section{Referência eletrônica}

Rodica Weitzman, «A introdução da explicação científica dos acontecimentos ambientais: focos de disputa entre o Setor Elétrico e os movimentos de Atingidos - Tucuruí, Pará», Anuário Antropológico [Online], v.47 n.1| 2022. URL: http://journals.openedition.org/aa/9309; DOI: https://doi.org/10.4000/ aa.9309

Anuário Antropológico is licensed under a Creative Commons. Atribuição-SemDerivações-SemDerivados CC BY-NC-ND 


\title{
A introdução da explicação científica dos acontecimentos ambientais: focos de disputa entre o Setor Elétrico e os movimentos de Atingidos - Tucuruí, Pará
}

The introduction of scientific explanations of environmental phenomena: forms of conflict between the Hydroelectric company and affected social groups - Tucurui, Pará

DOI: https://doi.org/10.4000/aa.9309

\author{
Rodica Weitzman \\ Museu Nacional/UFRJ, Rio de Janeiro, Rio de Janeiro - Brasil \\ Doutora em Antropologia Social pelo Museu Nacional/UFRJ e aluna de pós-doutoramento no Programa de \\ Pós-Graduação de Ciências Sociais em Desenvolvimento, Agricultura e Sociedade (CPDA/UFRRJ). Consul- \\ tora autônoma na elaboração e gestão de projetos sociais e na realização de pesquisas nos campos temá- \\ ticos de conflitos socioambientais, agricultura familiar e agroecologia, segurança alimentar e nutricional, \\ relações sociais de gênero e estratégias organizativas de movimentos sociais.
}

Este artigo destaca as mudanças nas ferramentas de luta empregadas pelos movimentos de atingidos a partir do agravamento dos impactos ambientais, tendo como base as inflexões dentro das cronologias apresentadas nos diversos registros. 0 recorte metodológico deste estudo é a construção de uma memória do vivido com base na análise de um acervo arquivístico que é gerado dentro de um processo de interação social. Os conjuntos documentais nos fornecem pistas para demonstrar a evolução das configurações organizacionais, desde as expressões embrionárias de resistência dos "desapropriados", "expropriados" e "atingidos", durante as fases iniciais de intervenção da empresa Eletronorte na região de Tucuruí, Pará, até sua adesão gradativa a um movimento abrangente e diversificado que tem como ápice a consolidação de repertórios de ação política face às alterações drásticas no quadro socioambiental. No cerne de conflitos entre aqueles que coordenam as intervenções e aqueles que são sujeitados/as aos efeitos visíveis e invisíveis deste modus operandi do mundo empresarial, a opção pela explicação científica dos efeitos ambientais por meio do desenvolvimento de pesquisas e da documentação cuidadosa destes dados empíricos se torna uma ferramenta potente de contestação das posturas institucionais da Eletronorte e dos seus aliados estratégicos.

Setor Elétrico; documentos; Atingidos; impactos; dimensão ambiental.
This article will analyze the shifts in the organizational strategies of the populations in Tucuruí, Pará, Brazil, during the period of intervention of the hydroelectric company Eletronorte in this region, that shifted when the environmental impacts became more visibly evident. The methodological approach of this study is the construction of a memory of events, based on the analysis of the collection of archives that are generated within processes of social interaction. The variety of documents produced provides a greater understanding of the evolution of organizational tactics, since the first expressions of resistance of affected groups during the early phases of the company's intervention, to the gradual consolidation of a large-reaching and diversified social movement, that has as its peak the creation of strategies of political action in the face of drastic alternations in the social and environmental context. At the heart of the conflicts that play out between those who coordinate the interventions and those who are subjected to the visible and invisible effects of this modus operandi of the business world, an option is made for the scientific explanation of environmental effects through the development of investigations and the careful documentation of empirical data. Such scientific methods become the most potent tool used by the affected social movements during confrontations of the institutional tactics and strategies implemented by the Eletronorte company and its allied forces.

Electric Sector; documents; affected populations; impacts; environmental dimension. 


\section{Introdução}

Este artigo tem como objetivo principal analisar alguns aspectos das várias fases de organização dos atingidos pela usina hidrelétrica (UHE) de Tucuruí no período de 1979 a 19901, no intuito de dar destaque às modificações que transcorreram nas suas estratégias de luta durante situações de conflito com o Setor Elétrico, organizações parceiras do setor privado e instituições governamentais. Nesse período de tempo, durante o qual houve uma transição democrática ${ }^{2}$, o território que foi afetado pela construção da barragem sofreu diversas transformações em razão das negociações árduas para a efetivação das indenizações e o processo de reassentamento das comunidades atingidas. Configurações organizacionais embrionárias foram se constituindo como e tornando-se sujeitos políticos coletivos, dedicados a dar visibilidade tanto aos efeitos socioambientais da obra quanto aos direitos que diziam terem sido desconsiderados pela empresa Eletronorte diante das reivindicações formuladas pelas comunidades que foram diretamente afetadas.

A intenção é entender de que modo a dimensão ambiental ganha centralidade enquanto elemento de argumentação e disputa entre os movimentos classificados como "atingidos", setores empresariais e instituições estatais, tendo como marco os problemas ambientais decorrentes à obra que foram se agravando a partir do ano de 1985. Neste contexto, a investigação e a comprovação científica dos fenômenos no plano empírico se tornam um pivô de divergências e atritos, ao mesmo tempo que representa um mecanismo imprescindível para o avanço das negociações. Como veremos a seguir, esta entrada pela "ciência" - enquanto caminho de contestação - representou uma mudança nos focos temáticos que eram predominantes anteriormente nas bandeiras de luta. A "ciência" - stricto sensu - é representada como um campo imparcial e equânime que transcende o plano das especulações, se tornando uma força propulsora de proposições voltadas para a reparação de danos dentro de suas estratégias.

Este trabalho busca decifrar os significados inerentes às estratégias de argumentação que eram construídas pela explicitação de fatos empíricos - apoiando-se na visão da "ciência" enquanto mecanismo de comprovação daquilo que é vivido no cerne da vida cotidiana que se valida por meio de abordagens alicerçadas na pesquisa e na investigação dos fatos. As formas de interlocução com o Setor Elétrico para buscar medidas de reparação de danos causados que fogem da lógica da mitigação são evidenciadas no amplo leque de documentos produzidos por uma diversidade de grupos e comunidades que se enquadram na categoria de "movimentos de atingidos". Esta categoria abrangente - "Atingidos" -, que se tornou uma nomeação predominante, abarcava comunidades indígenas, ribeirinhas, vazanteiros e pescadores, que eram "da jusante", localizadas abaixo da obra hidrelétrica no rio, e que se juntaram à população montante, ${ }^{4}$ que era formada por migrantes que moravam em "outros estados do nordeste e do sul" e que vieram para essa região justamente em função das promessas que foram lançadas ("Carta à Eletronorte", 3).

Para efetivar esta análise, tomo como base uma visão acerca dos conflitos so-
1 Este período foi escolhido como recorte temporal pelo Pro jeto de pesquisa intitulado: "As lutas dos atingidos pela usina hidrelétrica de Tucuruí - das primeiras mobilizações em contexto autoritário às condições de mobilização subsequentes à redemocratização do país", sob a coordenação do Prof. Henri Acselrad (Instituto de Pesquisa e Planejamento Urbano e Regional - IPPUR/UFRJ), dentro do qual se abriga este estudo. Este projeto de pesquisa foi construído com o objetivo de observar as diferenciações marcantes nas condições de mobilização dos atingidos e na natureza das ações intervencio nistas do Setor Elétrico antes e depois de 1985

2 Aqui faço referência ao processo de redemocratização no país, que acarretou uma mudança drástica no cenário político a partir do ano de 1985 .

3 A população de "Jusante" é descrita, em diversos documentos, como sendo de ocupação mais antiga e mais estável, em comparação com os outros segmentos. Nos documentos, a área de Jusante é retratada como sendo habitada por um povo que cultiva relações com o meio natural, vive da pesca e se desloca por meio fluvial.

4 "Montante" se refere à parte mais próxima da nascente do rio, e se localiza encima da parte denominada "jusante." Foi a população enquadrada como sendo mais afetada "diretamente" pela obra hidrelétrica no início do seu ciclo de implementação. 
cioambientais inspirada nas leituras de Sigaud (1992) e Acselrad (2004). É sabido que os projetos de grande envergadura - como a Usina Hidrelétrica em Tucuruí - desencadeiam "um conjunto de conflitos entre diferentes forças sociais" (Sigaud 1992, 34), tendo como ponto de partida destas situações conflitantes a intervenção estatal. Acselrad (2004) define "conflitos socioambientais" como processos deflagrados por modos diferenciados de uso e apropriação do território, nos quais seus significados estão no cerne da disputa, sendo foco de interpretações diferenciadas e re-formulações. São desencadeados geralmente a partir de pressões e ameaças sofridas por grupos sociais em função das práticas de intervenção de agentes externos e da distribuição de "externalidades". No caso da situação analisada, as tentativas de atestar o alcance dos danos ocasionados no meio ambiente colocam em questão a amplitude da ação intervencionista e suas repercussões. Portanto, o uso de métodos de verificação dos impactos ambientais se torna o fulcro das negociações entre o Setor Elétrico e as comunidades classificadas como atingidas, no intuito de ressignificar o que tem sido enquadrado pela empresa como uma mera "externalidade" - algo fortuito e fora do seu controle - para que seja compreendida como parte intrínseca de sua ação intervencionista.

Na visão da pesquisadora Lygia Sigaud ${ }^{6}$, as diferentes forças sociais que transparecem em situações de conflito "não estão dadas a priori, mas se constituem no próprio processo, a partir de uma estrutura social preexistente, da lógica de atuação do Estado, que varia historicamente, e também das alianças construídas e desfeitas" (Sigaud 1992, 34). Alinhada à abordagem analítica adotada por Sigaud (1992) acerca desta relação dinâmica entre a ação estatal e as respostas da população atingida, proponho focalizar as mudanças na estrutura das relações sociais na qual estão inseridas as diversas configurações organizacionais dos Atingidos em Tucuruí.

Assim, parto do pressuposto de que, embora as reações destes movimentos embrionários tenham sido fomentadas pela ação intervencionista da rede de organizações empresariais que se estende a partir da malha governamental, são forças sociais que não apenas reagem perante situações drásticas que colocam em risco sua sobrevivência econômica, expressões culturais e o quadro socioambiental no qual estejam inseridas ${ }^{7}$. São movimentos que atuam de forma protagônica, engajando-se ativamente na produção de "modos de subjetivação originais e singulares” (Guattari e Rolnik 2005). A novidade deste trabalho ${ }^{8}$ reside justamente na primazia atribuída às dinâmicas dos próprios movimentos dos Atingidos ${ }^{9}$ ao longo do tempo: isto é, as transformações nas estratégias de luta de agentes sociais que manifestam suas identidades coletivas através de um processo de territorialização. Para tal, parto de uma noção dos movimentos sociais enquanto espaços que proporcionam "formas de socialização política", ora "performances coletivas", ora "interações", e que constroem e reforçam "solidariedades e identidades coletivas" (Medeiros 2012, 24).

Destarte, meu interesse aqui é demonstrar de que modo as identidades destes povos são redefinidas situacionalmente em processos dinâmicos de mobilização desencadeados pelo agravamento das condições socioambientais destes terri-
5 "Externalidades" podem ser definidas como "os efeitos colaterais" de uma ação que envolve terceiros. Este termo se refere às consequências - negativas e positivas - para "terceiros" que não são levadas em consideração pela empresa ou indústria que executa a ação.

6 Em meados da década de 1980, Sigaud $(1986,1988)$ abriu uma nova linha de pesquisa que abordava, de modo frontal, as repercussões sociais das barragens hidrelétricas sobre os camponeses, com foco nas barragens de Sobradinho (no sertão da Bahia) e Machadinho (entre os estados do Rio Grande do Sul e de Santa Catarina). Na vasta literatura produzida por ela, Sigaud $(1986,1988)$ criticava incessantemente uma visão simplificadora do "social", que resultava na padronização das reações das populações atingidas perante os grandes projetos de desenvolvimento.

7 A visão apresentada vai na contramão da retórica atrelada a uma "noção vulgar dos impactos." (Sigaud 1986). De acordo com Sigaud (1986), o mundo empresarial tem propagado uma reificação das reações das populações atingidas, como se uma determinada opção tecnológica procedesse de modo semelhante em todos os contextos. A ênfase nos "efeitos substantivos" das obras hidrelétricas tende a destacar as dimensões culturais dos povos atingidos, em vez de sublinhar sua resposta política.

8 Há um amplo leque de estudos e pesquisas que têm sido realizados sobre os efeitos da obra em Tucuruí focando nas suas diversas fases, desde o início da implementação da obra (final dos anos 70) até a segunda fase depois do represamento do rio a construção das eclusas (anos 90), a partir de várias óticas: o processo de expropriação, o deslocamento compulsório e as negociações em torno das indenizações; as dinâmicas territoriais; a redistribuição espacial da população (Magalhães 1988, 1989, 1990, 1994, 2007; Fearnside 2015; Ravena 2009, 2015; Rocha 2008, 
tórios. Suas diversas estratégias organizativas - adotadas em diferentes marcos temporais de sua história - são expressas no amplo leque de documentos que foram produzidos, desde boletins e panfletos, os quais serviram para disseminar as principais bandeiras de luta destes atores sociais, até comunicados e cartas, que se tornaram meios de interlocução com o Setor Elétrico. ${ }^{10}$ Os documentos produzidos pelos movimentos dos atingidos fazem uso de mecanismos retóricos para atingir seu alvo - o Setor Elétrico -, ora por meio de linhas argumentativas embasadas em fatos empíricos, ora por meio de um discurso humanista -, na tentativa de sensibilizar e humanizar os/as agentes do mundo empresarial.

A espinha dorsal dos procedimentos metodológicos-teóricos que orientaram a elaboração deste artigo reside principalmente nos conjuntos documentais - tomados como um campo etnográfico -, os quais ordenam saberes e métodos de acordo com diferentes intencionalidades. Busco decifrar a constelação de significados atrelados a estes diversos documentos e as formas de sua instrumentalização dentro de um jogo contencioso de negociação entre atores sociais localizados em dois campos de disputa ao longo do período de sua implementação: por um lado, a empresa Eletronorte, responsável pela coordenação da obra e seus aliados e, por outro lado, as configurações organizacionais dos Atingidos. Neste sentido, é importante ressaltar algumas diferenciações neste processo de produção documental: enquanto a documentação produzida pelos grupos embrionários que faziam parte dos movimentos dos Atingidos representou uma poderosa ferramenta no seu processo de mobilização social, os documentos produzidos pelos agentes do Setor Elétrico eram veículos cuja principal finalidade era justificar e auxiliar suas estratégias de intervenção.

$\mathrm{O}$ acervo de documentos que foi consultado para finalidades da pesquisa realizada e cujos resultados são apresentados neste artigo se integra a um projeto que foi aprovado pela CAPES em 2015, dentro do edital no 12/2015, "Memórias Brasileiras: Conflitos Sociais", intitulado "As lutas dos atingidos pela usina hidrelétrica de Tucuruí - das primeiras mobilizações em contexto autoritário às condições de mobilização subsequentes à redemocratização do país", sob a coordenação do Prof. Henri Acselrad (IPPUR/UFRJ). De modo secundário, subsídios para as reflexões apresentadas aqui foram retirados de transcrições de algumas entrevistas realizadas por pesquisadores(as) envolvidos(as) no projeto no qual este trabalho se insere, com técnicos(as) de organizações de assessoria e lideranças dos grupos de base comunitária. Diante do caráter polifônico das informações contidas nos arquivos - assim como suas modalidades de uso - é inegável que os conhecimentos que compõem os conjuntos documentais se configurem, enquanto "um sistema de enunciados, verdades parciais, interpretações histórica e culturalmente constituídas - sujeitas à leitura e novas interpretações” (Cunha 2004, 292).

O ponto de partida do desenvolvimento deste artigo será uma contextualização tanto das formas de atuação da empresa hidrelétrica no contexto analisado, por um lado, quanto da construção da categoria classificatória - Atingidos - dentro dos processos organizativos, por outro lado, nos itens 2 e 3 . No item 4, o artigo pretende construir uma cronologia dos acontecimentos vividos pelas comunida-
2015; Novaes 2014, 2015). Esses trabalhos deixaram um legado importante no processo de construção deste projeto de pesquisa, dentro do qual este artigo se insere.

9 De propósito, o termo utilizado neste texto é "movimentos" no plural, porque "o movimento dos atingidos" não é algo monolítico e homogêneo, mas se subdivide em diferentes ramificações a partir de suas divergências e convergências. 10 É importante marcar aqui que estes registros (em forma de boletins e folhetos), que tinham como principal objetivo denunciar posicionamentos e estratégias exercidas pela Eletronorte, não foram publicizados amplamente. Foram socializados entre os seguidores e aliados dos movimentos embrionários de resistência nos focos locais e regionais. 
des atingidas e demonstrar a evolução das configurações organizacionais, que tem como ápice a consolidação de uma agenda política unificada em torno do agravamento do quadro dos impactos ambientais. Nos itens 5 e 6 - no cerne da linha de argumentação adotada -, pretendo demonstrar de que modo novas estratégias organizativas foram adotadas a partir de uma aposta na explicação científica por meio de estudos e pesquisas apoiados por novas parcerias institucionais. Até a parte conclusiva deste artigo, veremos de que modo os métodos de investigação, levados a cabo com o apoio de instituições acadêmicas e de pesquisa, comprovaram a relevância dos fenômenos que ocorreram no meio ambiente com base em dados empíricos, revelando as repercussões do uso da comprovação científica como ferramenta de luta e mobilização social.

\section{Contextualização da empresa hidrelétrica: suas intervenções no cam- po social e ambiental}

Para contextualizar melhor o estudo proposto, urge ressaltar alguns aspectos da instituição que se encarregou da operacionalização desta obra - a Empresa Eletronorte -, no período sob análise - 1979 a 1990. A Empresa Eletronorte foi criada a partir de uma articulação entre o ENERAM (Comitê Coordenador dos Estudos Energéticos da Amazônia) e o Ministério das Minas e Energia com o principal objetivo de potencializar a região Amazônia na produção e na transmissão de energia elétrica. ${ }^{11}$ Em um dos materiais produzidos pelo Setor Elétrico - "Eletronorte: 10 anos depois" (1983) -, transparece um campo semântico repleto de termos que sublinham as intencionalidades por trás de suas estratégias de intervenção: "centralizar o lugar”, “desbravar”, “civilizar." Nesses enunciados, a "UHE” se encaixa dentro de uma linguagem salvacionista, como a representação emblemática de um projeto que visa a "salvar o Nordeste do racionamento de energia elétrica" (s/d, 4).

No intuito de entender a lógica por detrás das estratégias de intervenção do Setor Elétrico, cumpre destacar de que modo as concepções sobre fatores de cunho "social" e "ambiental" são formuladas e evidenciadas no campo semântico do Setor Elétrico. Ao debruçar-se sobre os documentos do Setor Elétrico, percebe-se de que modo o tratamento das questões "sociais" e "ambientais", as quais são enquadradas pelo universo empresarial como meras "externalidades" que se traduzem em "custos indiretos" dentro dos estudos de "viabilidade socioambiental", nos revela um esforço empreendido pelo Setor Elétrico para garantir a produtividade do seu empreendimento a qualquer custo. Práticas institucionais são legitimadas pelo viés tecnicista e científico, tanto para comprovar a força dos acontecimentos no plano empírico quanto para embasar ações de "responsabilidade social" que poderiam aliviar as repercussões danosas de suas intervenções (Buttel 1992, Lopes 2004).

Uma visão dicotômica dos planos "técnico" x "ambiental" x "social” está na raiz do funcionamento e da operacionalização do Setor Elétrico no território brasileiro. No que tange à visualização do campo "social" dentro do plano de intervenção do Setor Elétrico, Castro (1988) aponta para a fusão entre a população atingida e
11 Cabe salientar que a geração da hidreletricidade no Brasil, até a proclamação da Constituição de 1988, foi fruto de decisões tomadas conjuntamente pelo Setor Elétrico e o Poder Executivo dentro de um processo de cogestão, de modo que as fronteiras entre os agenciamentos estatais e empresariais sempre fossem acinzentadas, especialmente durante o período do regime militar. 
o meio ambiente circundante, de modo que os dois elementos são visualizados como partes que integram o "objeto impactado" do empreendimento. Do ponto de vista deste autor, através de uma visão reducionista, o "ambiente" se restringe ao espaço de intervenção direta do Sistema Elétrico, sendo enquadrado como o objeto da obra de engenharia, acarretando uma "naturalização" da população atingida (Vainer 1993). A posição subordinada do fator "social" dentro do "projeto técnico", que se torna evidente nos diagnósticos e estudos de "controle ambiental", tem sido uma das causas geradoras de contestações e questionamentos apresentados pelos movimentos de atingidos perante o Setor Elétrico, especialmente no final dos anos 1980 e início dos anos 1990.

Esta tendência à "naturalização" da população atingida tem acarretado o que Sigaud (1987, 1988a, 1988b) chamava de uma "padronização" de suas reações perante os grandes projetos de desenvolvimento. O que merece destaque nestas medidas é a tendência, por parte da Eletronorte, de perder de vista as contradições no interior das sociedades, ao tratar distintos grupos sociais, repletos de diversidades, como unidades fechadas e homogêneas. Consequentemente, veremos que o plano de intervenção no campo "social", no início dos anos 1980 - com foco em indenizações e reassentamentos -, e no campo "ambiental" nos meados dos anos 1980 - com foco em pesquisas e ações compensatórias para aliviar danos no cerne dos territórios -, se organiza a partir de uma tentativa de transformar a "população atingida" em "beneficiários", sem considerar as especificidades dos segmentos contidos nestes agrupamentos.

O Setor Elétrico foi aprimorando suas abordagens com o apoio de um amplo leque de documentos que constituem "instrumentos de registro", os quais exprimem diferentes lógicas de funcionamento e operam a partir dos seus próprios sistemas de classificação. Neste conjunto de documentos, merecem destaque os "estudos ambientais" - os quais servem tanto para prever os efeitos da obra sobre o meio social e ambiental, quanto para relatar e mensurar os danos que foram ocasionados ao longo da implementação do empreendimento. Apareceram de forma tímida na fase anterior ao ano de 1985, durante a vigência do regime militar, e ganharam mais força no final dos anos 1980, marcados pela abertura democrática. É neste relato de "como se faz"12 que transparece justamente o aprimoramento de um saber especializado, chamado de "técnico", que é tão caro ao Setor Elétrico. Este enfoque tecnicista que transparece com tanta força revela a primazia atribuída aos "meios" empregados para cumprir uma "missão": a construção de uma obra hidrelétrica no território amazônico que se integra a um projeto civilizatório voltado para a aceleração da modernização.

Ao mesmo tempo, a partir do momento em que os impactos ambientais acarretam repercussões nocivas tanto para a flora e fauna do meio ambiente quanto para os seres humanos que ali residem, a posição subordinada dos fatores enquadrados como "sociais" e "ambientais" dentro do "projeto técnico", que se evidencia no bojo dos diagnósticos e estudos de "controle ambiental", se torna um dos pontos de questionamento por parte dos movimentos de Atingidos perante o Setor Elétrico. Assim, a fabricação de documentos ao serviço de estudos, pesquisas e planos
12 Alguns documentos produzidos pelo Setor Elétrico ("Usina Hidrelétrica Tucuruí: Memoria Técnica” - 1989; "Relatório Interno da Eletronorte", 02/01/89; "Tucuruí - 10 anos depois”, 1983) que destrincham este modo de "fazer" foram peças-chaves no esforço de construir uma memória da adoção de processos técnicos em diversas fases da implementação da obra hidrelétrica. Este acervo de documentos que exprime uma "memória técnica" resgata elementos do passado para ordenar sua própria prática em nível institucional, além de justificar as bases de suas estratégias de intervenção no cenário público. 
é o pivô de um processo intenso de contestação e mobilização social.

\section{A maleabilidade das identidades coletivas - De "expropriado" ao "atingido"}

Para se tornar mais inteligível a análise das bandeiras, ferramentas e discursos que são instrumentalizados no seu campo de atuação perante o Setor Elétrico, é importante assinalar algumas ponderações sobre as modalidades organizativas dos grupos que faziam parte da categoria identitária - "atingidos" - e suas formas de autoclassificação.

Como veremos ao longo deste artigo, "Atingido" é uma categoria em disputa (Vainer $2008)^{13}$, uma vez que as nomeações vão sofrendo transformações ao longo dos anos para se adequar melhor à posição política que a categoria adquire e aos interesses de cada ator social que se envolve diretamente com a construção destas nomenclaturas. É interessante observar, por exemplo, que quando examinamos os documentos oriundos dos movimentos sociais dos anos 1980 a 1985, aparece com frequência a categoria "desapropriado" ou "expropriado," o que faz sentido diante de uma leitura do mundo empresarial como usurpador das terras, que se engaja em um processo violento de "desapropriação" em nível territorial. A frequência deste termo provavelmente deriva de sua potência política, pelo fato de que denota o desenraizamento destes povos que foram literalmente tirados de sua base territorial.

Havia uma distinção entre a população afetada diretamente, ao redor do lago, e "as famílias na região jusante embaixo da barragem", que formalmente não faziam parte da área de intervenção da Eletronorte, uma demarcação que foi reforçada nos estudos rotulados como "preliminares": "os Estudos de Inventário e Viabilidade" ${ }^{14}$ no final dos anos 1970. Aida Maria Farias da Silva, uma assessora que deu suporte aos processos organizativos das comunidades atingidas no período de 1981 a 1989, destacava a existência de "duas pautas" de acordo com um recorte geográfico: "uma pauta de baixo" e "uma pauta de cima" (Entrevista realizada em 17/agosto/2017, Brasília/DF).

Assim, no final dos anos 1980, o termo "Atingidos" denota o processo de ampliação dos efeitos perceptíveis da intervenção da UHE, no sentido de incluir aqueles que sofreram com o alagamento da região - direta ou indiretamente -, como foi denunciado em alguns documentos produzidos nesta época. Na década de 1990, quando os vínculos entre a CAHTU - Comissão dos Atingidos pela Barragem e o MAB - Movimento dos Atingidos por Barragens se tornaram mais estreitos, houve uma ressignificação do termo "atingido" a partir da politicização de um discurso que tinha como esquema referencial um quadro analítico mais abrangente, no qual as reivindicações foram recontextualizadas dentro de uma linguagem militante que criticava, de forma veemente, as estruturas que sustentam sistematicamente práticas de expropriação material e desestabilização sociocultural das populações diretamente e indiretamente afetadas. Esta transição nos focos dos processos organizativos, que se revela nos discursos que foram empregados e nas ferramentas que foram instrumentalizadas nos processos de negociação perante os atores do Setor Elétrico, será examinada mais a fundo nas próximas seções.
13 No artigo "Conceito de 'Atingido': Uma Revisão do Debate", Vainer (2008) analisa as evoluções no conceito "atingido" ao longo do tempo, a partir da ótica do Setor Elétrico. De acordo com o autor, o conceito "atingido" foi primeiramente abordado a partir da concepção territorial-patrimonialista, o que constituía a base das políticas indenizatórias; em um segundo momento, o "atingido" foi reconhecido a partir de uma concepção hídrica, como "inundado", o que engloba outras categorias que não tinham sido consideradas anteriormente, como "posseiros" e "meeiros"; finalmente, a partir da segunda metade dos anos 1980, a legislação ambiental emergente provoca uma redimensionamento do conceito para além daquele deslocado meramente por conta do reservatório, de modo que fossem incorporadas as mudanças sociais, culturais e econômicas no quadro analítico.

14 Os "Estudos de Inventário e Viabilidade" fundamentaram os Projetos Básico e Executivo da UHE - Tucuruí no início dos anos 1970. Esses estudos foram realizados a partir de um consórcio firmado entre as instituições Engevix e Ecotec em $31 / 07 / 72$, e foram apresentados formalmente ao DNAEE - Departamento Nacional de Águas e Energia Elétrica em 1974, junto com o pedido de concessão para a exploração do potencial energético do rio Tocantins no ponto estudado. 


\section{Evolução dos focos e das estratégias das mobilizações dos movimen- tos de Atingidos até meados dos anos 1980}

A seguir, mostrarei a evolução dos processos organizativos dos movimentos de Atingidos, ressaltando os focos temáticos que constituíram "bandeiras políticas" até o ano de 1985, quando o agravamento de impactos no meio ambiente acarretou uma mudança nos focos temáticos postos em destaque dentro do seu repertório de ações coletivas.

No período de 1978 a 1985, os movimentos embrionários de atingidos se mobilizaram de forma veemente, se apoiando em uma crítica contundente da condução dos processos indenizatórios e das proposições dos agentes do Setor Elétrico para efetivar o reassentamento de diversos grupos sociais - vazanteiros, pescadores, lavradores e assim por diante - para outras áreas. A primeira bandeira de luta disseminada amplamente pelos movimentos embrionários evocava a noção de "indenização justa" pelas terras e benfeitorias por meio da introdução das seguintes palavras de ordem: "Terra por terra", "Casa por Casa, Vila por Vila" nos diversos documentos produzidos e disseminados.

Os empecilhos nos processos de negociação eram relacionados aos significados atribuídos a cada uma das "palavras de ordem" que compunham a agenda política dos movimentos de Atingidos, as quais se diferenciavam drasticamente dos enquadramentos conceituais trazidos pelo Setor Elétrico. De acordo com Vainer (2008), a abordagem dos grandes projetos de desenvolvimento tem sido historicamente norteada pela estratégia "territorial-patrimonialista", quase sempre "indenizatória", dentro da qual a população é tomada "como um obstáculo a ser removido, de modo a viabilizar o empreendimento" (Vainer 2008, 41), por meio da negociação dos valores da desapropriação a partir de uma tática de tratamento "caso a caso" (proprietário por proprietário) por parte do Setor Elétrico. Vainer (2008) afirma que o tratamento focado no individuo/unidade familiar constitui "uma prática constante do Setor Elétrico, na esperança de que a recusa em se sentar à mesa de negociações acabe por inviabilizar a legitimação da representação e, em consequência, deixe o campo aberto aos acordos individuais" (Vainer e Araujo 1992, 23). Além desta abordagem vertical, embasada no tratamento "caso a caso", houve também expressões de vários tipos de pressão, no intuito de forçar a subordinação das pessoas e comunidades às regras dos processos indenizatórios.

Na contraposição desta abordagem imposta verticalmente pelo Setor Elétrico, houve uma recontextualização das demandas, de modo que a "terra" e a "casa" eram abarcadas como direitos a serem reivindicados a partir de definições elásticas e expansivas, possibilitando pensar além dos enquadramentos associados a cada uma destas categorias analíticas e operativas. Ao evocar o lema "Casa por Casa", os agentes do Movimento dos Atingidos que foram autores do Boletim "Arca dos Moradores da área do reservatório Barragem de Tucuruí” destrinchavam seus entendimentos desta premissa: "Que a Eletronorte construa novas vilas com casas melhores ou iguais às anteriores, luz, esgoto, água, ruas e prédios públicos” 
(Arca dos moradores da área do reservatório Barragem de Tucuruí, 1982 e 1983, 6). Aqui também é perceptível uma visão mais ampla da moradia, que vai além da estrutura física de uma casa e engloba a infraestrutura do local que rodeia a morada habitada.

A seguinte frase, emitida pelos Vazanteiros, expressa sua visão acerca do lugar para onde pretendiam ser reassentados: "E ao sair, exigimos um lugar igual ou melhor do que este: que apresente possibilidade de pesca, caça, colheita da castanha, com garimpo e terra para trabalhar" (Extra informativo Itupiranga, n. 4, abril 1979 , 4). Questionamentos como estes apontam para a necessidade de considerar fatores que intermedeiam sua relação com a terra e afetam a rentabilidade de sua produção, como o tamanho e as condições dos lotes de terra (ex: terras férteis, próximas aos rios, etc.), levando em consideração a diversidade das atividades produtivas desempenhadas por estes grupos sociais e sua relação simbiótica com fatores socioambientais.

Nesse período inicial de mobilização - de 1978 a 1985 -, os grupos sociais que sofriam os efeitos da UHE expressavam sua frustração diante de suas diversas tentativas afanosas e improfícuas de "atingir" a Eletronorte, seja por meio de cartas, atas ou reuniões presenciais de diálogo e negociação, todas as quais não desencadearam repercussões nas posturas do Setor Elétrico. A dificuldade de alcançar o Setor Elétrico por meio de diversas táticas no campo da negociação provocou a realização de outras estratégias de enfrentamento e contestação, como os três acampamentos que foram levados a cabo entre 1982 e 1984. Nestes eventos, que tinham o principal objetivo de fazer pressão política sobre as autoridades - muitos dos quais tiveram como desfecho final a construção de acordos -, os limites de processos de negociação pautados na troca de cartas e comunicados foram sinalizados.

\section{Novas problemáticas e novas respostas: o foco ambiental ganha cen- tralidade na plataforma de reivindicações}

A partir de 1985, houve uma mudança nos grandes eixos da plataforma de reivindicações perante uma precarização das condições socioambientais e seus efeitos decorrentes, que ganharam expressividade nos diversos territórios. As demandas expressas se ampliaram para além das reivindicações mais antigas e emblemáticas, como "Terra por Terra" e "Casa por Casa", embora estas demandas perdurem como pano de fundo nas denúncias e provocações que são registradas nos diversos comunicados. Há um deslocamento para novas problematizações dentro dos repertórios de ação política, o que joga luz nas especificidades de cada um dos segmentos que compõe a categoria de "Atingidos", como as comunidades tradicionais (vazanteiros/as, ribeirinhos/as, pescadores/as) que habitam as áreas mais afetadas pela ação da UHE. Um dos elementos notáveis deste estágio do processo organizativo é a expressão de uma consciência mais acurada sobre a cadeia de causas e efeitos de cunho social e ambiental deflagrada pela obra hidrelétrica, que vem sendo externalizada tanto nas reuniões efetivadas com agentes do Setor Elétrico quanto nos documentos produzidos e entregues para diversos órgãos, 
incluindo a Eletronorte. .

Esta consciência se tornou mais explícita quando os Atingidos perceberam a ligação entre a crise ambiental, vivenciada de forma aguda ao nível dos territórios a partir do ano de 1985, e os dois fenômenos que tinham acontecido anteriormente a ela: primeiramente, o alagamento e, em seguida, a crise dos mosquitos.

O alagamento ocorreu em 1985, em algumas áreas de reassentamento, quando se fechou o reservatório, em função da subida da água 6 metros acima do planejado, o que chegou a impactar 1500 famílias além do número originalmente previsto. No Ofício $n^{\circ} 35$, elaborado em $27 / 03 / 1985$, os movimentos expressaram seu "lamento pela irresponsabilidade da Eletronorte, que se caracteriza pela incapacidade de seus técnicos em prever a área a ser atingida pelo lago, reassentando 50\% da população rural em área inundável" (Ofício $\left.n^{\circ} 35,27 / 03 / 1985,2\right)$. Em meados dos anos 1980, veremos de que modo a alegação feita por parte dos Movimentos dos Atingidos de que "a vida das pessoas está muito pior depois do alagamento" é corroborada, uma vez que o fenômeno do alagamento é associado a uma cadeia de acontecimentos perniciosos que foram desencadeados no período após o enchimento do reservatório. Assim, percebe-se de que modo se sedimentou uma conexão entre a inundação e os problemas socioambientais na percepção dos fatos.

Outra bandeira de luta que reforçou a temática ambiental dentro da agenda política dos Movimentos dos Atingidos foi a proliferação incomum dos mosquitos. A praga dos mosquitos se iniciou no final de 1984, quando ocorreu o barramento do rio, surgindo na zona rural de Novo Repartimento e de forma mais intensa ainda na Gleba Parakaña, onde se estendeu até os anos de 1994 e 1995. Desde o início, os movimentos sinalizaram que o criadouro dos mosquitos era o lago da UHT, o que evidenciou o papel da Eletronorte e de suas instituições parceiras em sua ocorrência.

No que diz respeito às estratégias de mobilização das comunidades atingidas a partir desta crise dos mosquitos, cabe salientar algumas formas mais diretas de pressão, como um acampamento dos expropriados no portão principal da Eletronorte que teve destaque na imprensa local e nacional. De acordo com algumas lideranças, este ato político foi determinante na criação de uma Comissão Interministerial Pró-População a Montante de Tucuruí em 1992, como uma resposta institucional por parte do Presidente da República.

O Relatório produzido por essa Comissão, que apresentou conclusões sobre as causas da praga dos insetos, foi apropriado pelos Movimentos dos Atingidos como arma de sua luta política, servindo como uma base de subsídios para suas estratégias discursivas em diversos documentos fabricados posteriormente à data de 1992. Isso demonstra claramente os modos distintos de fazer uso dos documentos, de acordo com as intenções de cada ator envolvido, uma vez que todo acervo arquivístico é gerado dentro de um processo de interação social. (Cunha 2004). O amplo leque de documentos que são fabricados no bojo do universo empresarial - e depois rearranjados e reestruturados a partir de interpelações com os movimentos dos Atingidos - desvela regimes de verdade que são flexibilizados com base em diversos sistemas de significados. 
Vale ressaltar alguns elementos do Relatório que foram extraídos para o exercício analítico que era vivenciado pelas pessoas que participavam dos movimentos dos Atingidos. O objetivo era apontar os erros cometidos e exigir medidas compensatórias que pudessem aliviar os efeitos dos danos ocasionados. Neste sentido, de forma minuciosa, desvelam as conexões entre a crise dos mosquitos, a inundação da margem do lago e "a proliferação de uma vegetação aquática flutuante, macrófita.” (Acselrad e Silva 2004, 9). Tal vegetação é identificada como a origem do advento desses mosquitos "na reentrância da margem do lago.” (id., 9).

No Relatório da Comissão Interministerial Pró-População a Montante de Tucuruí (1992), em uma entrevista efetivada com um líder sindical, morador do Rio Gelado (mar/1996), há confirmação da hipótese apresentada, revelando que as falhas no trabalho de desmatamento pela instituição encarregada de tal tarefa - a empresa Capemi, resultaram no acúmulo desta vegetação flutuante e submersa no lago em 1983. Em uma entrevista concedida pela Aida, ela esclarece que "quem na época ganhou a concorrência para desmatar a área do que ainda tinha de floresta para formação do lago foi a Capemi, a caixa de pecúlio dos militares." Ela alega que a Capemi se constitui enquanto uma empresa que falhou no processo de desmatamento da área para ser alargada, utilizando-se de produtos químicos como "Pó da China" e o "agente laranja", que acabaram deixando a área "envenenada" (Acervo "Memórias Brasileiras: Conflitos Sociais", Projeto IPPUR/UFRJ, Entrevista concedida em 17/ agosto, 2017, Brasília/DF).

De acordo com o Boletim da Pastoral Juvenil de Abaetetuba, produzido em julho de 1984, "A Voz dos Jovens”, “a vegetação submersa irá apodrecer e se tornar gás sulfídrico, contaminando a flora, fauna e a vida de todos que vivem na região" $(1984,12)$. A seguinte frase, que aparece na Carta do SRT a Prelazia de Cametá, é emblemática de uma leitura crítica acerca das repercussões negativas no meio socioambiental: "No fundo do lago estão quatro cidades e várias vilas, cemitérios, fossas" "“Carta do SRT a Prelazia de Cametá, às entidades democráticas e às comunidades cristãs" - 1987, 5). De forma categórica e incisiva, os depoimentos expostos aqui corroboram a hipótese de que os impactos nocivos que foram desencadeados e agravados, tanto pelo enchimento do reservatório quanto pelo alagamento da área, encontram sua fonte originária nos erros técnicos gravíssimos cometidos por Eletronorte e pelas organizações e empresas aliadas a ela, algumas das quais foram contratadas para diversos serviços, entre eles o desmatamento da área atingida.

Na produção documental, as lideranças dos movimentos sociais vêm formulando hipóteses que iluminam a teia de relacionalidade entre um conjunto de acontecimentos: inundação, desmatamento, praga de mosquitos e surgimento de doenças. Esta leitura sobre a ligação entre diversos conflitos socioambientais ocupa um lugar de centralidade nos seus discursos e na sua agenda política, de modo que provoca o que Acselrad nomeia de "uma nova articulação ambiental do conflito”. Autores como Acselrad e Silva $(2011,68)$ apontam que

embora utilizando "a questão dos mosquitos" como uma pauta específica, 
o movimento organizado, com apoio do Sindicato dos Trabalhadores Rurais de Tucuruí e suas subsedes, colocou-se à frente das negociações, denunciando diferentes situações vivenciadas pela população desde o início do processo expropriatório (id., 2001, 68).

\section{Mudanças na agenda política dos Atingidos: a formulação de novas respostas diante do quadro socioambiental}

Uma série de alterações ambientais, como a contaminação de algumas espécies de peixes, a mudança na cor da água, a diminuição na produção de cacau e açaí, o agravamento de doenças do aparelho digestivo e a invasão de insetos, todas as quais foram agravadas no Rio Tocantins depois da formação do lago, recaíram com mais intensidade sobre a população de Jusante. Isso certamente provocou seu maior engajamento nos atos públicos, reuniões e assembleias que foram realizados para tratar destas questões a partir do ano de 1987.

O discurso de alguns segmentos também foi se moldando de acordo com o agravamento do quadro socioambiental no território afetado. Alguns segmentos que ocupam a área de jusante, como os Vazanteiros, sinalizavam seu estado de vulnerabilidade social perante fenômenos socioambientais, tanto a mudança na qualidade da água, que se revelou extremamente desastrosa para finalidades da pesca e irrigação, quanto o assoreamento dos rios, que acarretou perdas na produtividade em função da interrupção do fluxo de nutrientes nas regiões de Várzea.

Desde o início da obra, o Setor Elétrico não contemplava os grupos sociais que ocupavam a área de "jusante" como parte da população diretamente atingida dentro dos mapeamentos da área de intervenção. Nos estudos de viabilidade ${ }^{15}$ que antecederam as fases de intervenção e que foram concluídos em dezembro de 1974 e junho de 1975, o projeto técnico foi projetado para intervir estritamente na área do reservatório e imediações, uma vez que não foram realizados estudos complementares de jusante e regionais (Coppe/UFRJ, 1999; Eletrobrás/Comase, 1991/1993; Eletronorte, 1987). Por conseguinte, aqueles que habitavam áreas fora do perímetro do futuro lago, e que, em vista disso, nas previsões feitas, não seriam sujeitas às inundações, como os "vazanteiros" e "ribeirinhos", foram excluídos das políticas de indenização e reassentamento. (Acselrad 2011). Ao agravar os efeitos socioambientais, a partir da poluição das águas que serviam como fonte de sobrevivência para estas comunidades tradicionais, este enquadramento da área atingível e daqueles a serem afetados "diretamente" ou "indiretamente" teve que ser ajustado. É importante sinalizar que quem era rotulado como alvo indireto dos efeitos da barragem passa a ser considerado um alvo direto a partir do enchimento do reservatório e da inundação das águas acima do nível previsto. Assim, as comunidades localizadas na região "jusante" foram incorporadas nas conceituações da "população atingida" pelo Setor Elétrico a partir de uma nova projeção da área de intervenção e do alcance dos impactos da UHE, embora esta nova formulação apenas se consolidasse por meio de comprovação científica e das pressões por parte de diversos atores sociais, como veremos a seguir.
15 Vainer (1993) explica os significados da noção de "viabilidade socioambiental", que embasava estes estudos preliminares e norteava as estratégias políticas de controle e prevenção de conflitos. De acordo com esse autor, estes estudos de "viabilidade socioambiental" tinham o principal objetivo de "assegurar condições para que a tomada de decisões e a implementação de ações sejam sobretudo de natureza preventiva e ocorram em tempo hábil, de modo a evitar impasses decorrentes de conflitos de interesses mal equacionados e custos econômico-financeiros elevados para o Setor" (Vainer 1993, 139). 
De acordo com técnicos da CPT que assessoravam o Movimento naquela época, o movimento ganhou força com a entrada do "jusante", uma vez que "a população ribeirinha localizada na jusante da barragem tinha uma experiência maior de organização, vinda das comunidades de base e passando pela conquista das direções dos sindicatos, o que, sem dúvida, levou a resultados diferentes." (“Ata da Reunião dos Atingidos pela Barragem de Tucuruí”, dias 12 e 13/03/1989, 7).

A pressão política exercida pelos sindicatos e pelos movimentos de pescadores, ribeirinhos e vazanteiros organizados que habitavam a região "abaixo da barragem" - a "jusante" - foi canalizada por meio de uma série de reuniões que aconteceram a partir de março de 1987 com a Eletronorte. Estas reuniões de negociação - muitas das quais envolveram a empresa responsável pela realização de pesquisas socioambientais Engevix - foram voltadas tanto para "discutir os efeitos da barragem" quanto para "exigir pesquisas de água, plantas e peixes" (Documento: "Ata da reunião dos atingidos pela barragem de Tucuruí - 12 e 13/03/1989", 8). Em entrevista realizada com Felisberto Demasceno, ele cita o envolvimento de mais um ator social nesta fase "final da luta" durante meados dos anos 1980: o âmbito acadêmico, englobando a Universidade Federal do Pará e alguns núcleos de pesquisa (Acervo Memórias Brasileiras: Conflitos Sociais”, Projeto IPPUR/UFRJ, Entrevista concedida em 17 de agosto, 2017, Brasília/DF). De acordo com ele, os/ as pesquisadores/as e professores/as destas instituições acadêmicas "vieram em apoio", para fazer "alguma discussão sobre o que aconteceria a Tocantins com o fechamento do rio". De alguma maneira, alertaram as lideranças das comunidades atingidas sobre impactos que poderiam se tornar perceptíveis no futuro próximo, como o desaparecimento de algumas espécies de peixe e a salinização da água do Rio Tocantins.

Nessa fase, houve uma mudança acentuada nas estratégias de ação política, uma vez que os Movimentos de Atingidos optaram pela atestação científica como o caminho mais indicado para pressionar as autoridades do Governo e da Eletronorte a implementar diversas providências políticas. Isso fez com que a "luta por pesquisas e estudos" dos impactos socioambientais se tornasse o foco central da plataforma de reivindicações e do plano de ações em meados dos anos 1980. Por exemplo, a falta de "estudos científicos" na etapa inicial da obra que pudessem prever e prevenir problemas socioambientais foi alvo de crítica por parte dos movimentos de Atingidos e seus assessores no bojo deste processo árduo de negociação. Aida, ex-técnica do CPT, foi bastante incisiva nas suas críticas à Eletronorte pela implementação de ações de reassentamento sem terem sido feitos estudos prévios de "impacto ambiental e social":

(...) Parecia tudo muito novo pra Eletronorte. Ela, como não tinha estudos, foi feito na marra assim, foi feito um estudo de viabilidade técnica sem estudo de impacto ambiental e social. Demoraram a ver com clareza onde é o impacto, que impacto? Não existe. Tu pega os estudos do Tucuruí, existia apenas os estudos de viabilidade técnica. Esse rio tem viabilidade pra ser uma grande barragem por essa e essa razão. Não existia, paralelo a ele, 
nenhum estudo de impacto ambiental de nada...(...). E aí, ela não tinha. Como ela não tinha, ela não conseguia prever (Entrevista realizada em 17 17/agosto/2017, Brasília/DF).

Desde seu ponto de vista, se tivessem sido implementados estudos ou pesquisas focados nos aspectos socioambientais durante o processo inicial de mapeamento da área de intervenção em 1979, existiria um maior respaldo para a busca de soluções durante as etapas posteriores. Inegavelmente, este processo de contestação protagonizado por Aida, assessora dos movimentos de atingidos, e também por integrantes das comunidades classificadas como Atingidas que, paulatinamente, se estruturavam enquanto um movimento organizado, tinha como fulcro central o manejo do campo "social" e "ambiental", tanto nos documentos fabricados pelo Setor Elétrico quanto nos instrumentos utilizados para auxiliar suas estratégias de intervenção. Esta problematização acarretou uma desestabilização do plano "técnico" enquanto plano inquestionável que garante a infalibilidade das intervenções, sem considerar estes fatores do campo socioambiental.

Um ponto de destaque neste processo de negociação foi o engajamento bastante saliente de uma diversidade de atores sociais - movimentos de atingidos e organizações de assessoria, como o CPT, que se juntaram a um conjunto de instituições acadêmicas e de pesquisa. Esses atores envolveram-se nos seguintes procedimentos: construção metodológica das pesquisas, análise dos seus resultados, armação das proposições para aliviar os danos ambientais, e implementação de medidas compensatórias. Em um relato do processo organizacional vivido naquele período, um representante do STR de Cameta lembra da força coletiva expressa pelos movimentos envolvidos que "não abriram mão até que eles realizassem as pesquisas" e que teve como resultado final "de nossa pressão, os convênios que estão fazendo com os Prefeitos" em torno de ações de assistência para a população perante o aumento de doenças e outras aflições ("Ata da Reunião dos Atingidos pela Barragem de Tucuruí" - dias 12 e 13/ março 1989). Tanto as ações voltadas para medir os efeitos dos problemas socioambientais quanto as medidas compensatórias que foram desenhadas com a intenção de responsabilizar vários atores sociais pelas falhas que cometerem (Prefeituras, Eletronorte e a organização contratada - Engevix) deixaram um legado insubstituível: uma espécie de "unidade moral e cognitiva" (Durkheim 1995 [1912]) no interior dos Movimentos de Atingidos.

Um ponto de destaque neste processo de mobilização social protagonizado pelos Atingidos foi a apropriação da linguagem e da argumentação ambiental para embasar seus conflitos com seus oponentes - o Setor Elétrico - dentro de um campo de disputa (Lopes 2006). O antropólogo Sérgio Leite Lopes (2006), que endossa uma visão da "ambientalização dos conflitos sociais" enquanto "uma nova questão pública", demonstra alguns casos nos quais movimentos sociais organizados adquiriram uma linguagem "biologizante", "médica" ou de "saúde" no bojo dos seus conflitos com autoridades de fábricas ou órgãos públicos. Da mesma forma, na região de Tucuruí, percebe-se que, a partir do surgimento de processos conflituosos englobando mudanças ambientais, os grupos sociais atingidos - pescadores, 
ribeirinhos, vazanteiros - passaram a utilizar termos e fazer uso de procedimentos e ferramentas que não faziam parte nem do seu campo semântico nem do seu repertório de bandeiras políticas.

Deste modo, as armas da "luta" foram se ampliando para englobar a "neutralidade" e a "imparcialidade" da ciência, que, a partir das certezas apresentadas, afirmava a obrigatoriedade de ações incisivas no campo ambiental. Com base nas comprovações de danos ocasionados no meio ambiente por meio de métodos científicos, os movimentos atingidos - compostos por pessoas que habitavam o "Montante" e "Jusante" do Rio Tocantins - encontraram fundamentos sólidos para abrir novos caminhos de negociação.

\section{Conclusões finais}

Da mesma forma que houve modificações nas estratégias, focos temáticos e ferramentas das lutas dos segmentos que fizeram parte do Movimento dos Atingidos no período de 1979 a 1990, também houve alterações na sua composição, a partir da ampliação do processo de territorialização, e a incorporação de demandas específicas, relacionadas com as distintas formas de conviver com os fluxos do Rio Tocantins. Situações inusitadas e demandas novas geraram novas respostas, acarretando modificações no tom das negociações e na natureza das reivindicações perante o Estado e a Empresa Eletronorte. É importante ressaltar as alterações na maneira pelas quais as reivindicações foram produzidas, sustentadas, contestadas e alteradas, a partir de processos de interação social nos meados dos anos 1980.

Inevitavelmente, as condições do contexto político influenciaram o processo de mobilização dos movimentos dos Atingidos, sendo um condicionante que tanto limita quanto possibilita o maior alcance de sua ação política, dependendo do momento histórico. As comunidades atingidas pela obra hidroelétrica abarcaram várias pautas (como a pauta dos "alagados"), ampliando progressivamente seu repertório político de acordo com um contexto mutável e oscilante. As queixas não eram direcionadas apenas para as lacunas detectadas nas abordagens adotadas, como a insuficiência das medidas compensatórias para atender as populações atingidas. Nos meados dos anos 1980, as reivindicações passaram a ser mais propositivas, a partir de um questionamento dos critérios que determinaram sua eficácia em termos "técnicos". Logo, novas bandeiras foram erguidas, como a "luta por pesquisas e estudos". Neste contexto turbulento e conflituoso, os documentos desempenharam um papel central, sendo enquadrados como objetos vivos que passam por um processo de ressignificação, se tornando armas de luta para os Atingidos perante o Setor Elétrico.

Ao incorporarem as especificidades das populações vazanteiras e ribeirinhas, que historicamente tinham sido ignoradas ou omitidas dos processos de formulação de medidas compensatórias (Sigaud 1983, 1987, 1988, 1992; Vainer 2008, 1992), os movimentos de Atingidos conseguiram pôr em destaque uma série de reivindicações que envolvem a recontextualização do ambiente circundante. Logo, no bojo do seu processo de mobilização, houve uma valorização das dimensões 
culturais presentes na ação coletiva, a partir de uma atenção voltada para as especificidades dos segmentos que compõem esta categoria identitária - Atingidos -, alargando assim a esfera do que se pode considerar como o "político" dentro de um repertório que englobava ações de enfrentamento, embate e negociação. Destarte, o regime de verdade que rege a gestão destes "movimentos" no cerne das dinâmicas sociais é flexibilizado de acordo com diferentes óticas, abordagens e critérios, testemunhando a vitalidade e a força de um movimento heterogêneo que se constrói no plural, a partir de um recorte temporal e espacial.

Recebido em 21/05/2021

Aprovado para publicação em 01/02/2022 pelo editor Alberto Fidalgo Castro 


\section{Referências}

\section{Documentos internos do acervo constituído no IPPUR/UFRJ sob a coor- denação do Prof. Henri Acselerad (IPPUR/UFRJ):}

Ata. 1984 (10-11 de novembro). Ata da reunião realizada entre Centrais Elétricas do Norte do Brasil, Eletronorte e Comissão Representativa dos Colonos Expropriados. Brasília.

Ata. 1989 (12-16 de maio). Encontro dos Sindicatos de Trabalhadores Rurais e Colonias de Pescadores atingidos pela UHE de Tucuruí. Tucuruí.

Ata. 1987 (28-29 de março). Ata de Encontro entre a Eletronorte, Engevix e Sindicato de Trabalhadores Rurais da Região Tocantina.

Boletim. 1982 (setembro) - 1983 (janeiro). Arca dos Moradores da área do reservatório Barragem de Tucuruí.

Boletim. 1979 (abril). Extra informativo Itupiranga 4. Tucuruí.

Boletim.1981 (maio). Tucuruí Urgente. Tucuruí.

Boletim. 1982 (2 de dezembro). Luta dos Desapropriados. Tucuruí.

Carta. 1980 ( 9 de janeiro). Carta a Eletronorte. Tucuruí.

Coleção do Museu de Eletricidade. s/d. Apresentação: "A UHE Tucuruí e a Promoção do Desenvolvimento Regional".

Documento. 1989 (13 de novembro). Tucuruí - Colonos e Índios x Eletronorte. Secretaria do Estado de Agricultura do Pará e Centro de Educação Pesquisa e Assessoria Sindical e Popular. Marabá - PA.

Documento. 1989 (12-16 de maio). Encontro dos Sindicatos de Trabalhadores Rurais e Colonias de Pescadores atingidos pela UHE de Tucuruí.

Documentos I, II, III. 1981 (12 de dezembro) - 1982 (12 de agosto). Denúncia e Reivindicação da Populacão dos Vazanteiros de Itupiranga, Tauri e Moradores da Localidade da Rainha e Morajuba Direta, atingidos pelo Projeto da UHE de Tucuruí - Reservatório. Tucuruí.

Documento. 1982 (12 de agosto). Denúncias e Reivindicações da População de Repartimento Breu Branco e Adjacências, dos Vazanteiros de Itupiranga, Tauri e Moradores das Localidades Rainha e Maratuba Direta, Atingidas pelo Projeto do Reservatório da UHE - Tucuruí. Tucuruí.

Documento. (1981, 2 de novembro). Documento dos Vazanteiros da Itupiranga à Eletronorte. Tucuruí.

Documento. (1985, 2 de maio). Documento de Reivindicações da Comissão dos Expropriados. Tucuruí.

Documento. (1984, 21 de outubro). Documento da População de Expropriados ao Governador do Estado do Pará Dr. Jader Fontenelle Barbalho. Tucuruí.

Documento. 1987. Eletronorte. UHE Tucuruí: Plano de Utilização do Reservatório Versão 4 - Preliminar. Tucuruí.

Fichas de levantamento. 1989. Comissão dos Moradores da Colônia do Mojú. Tucuruí.

IPPUR. 2017. Entrevista com Aida Maria Farias da Silva. Concedida em 17/agosto/2017, Brasília/DF. 
IPPUR. 2017. Entrevista com Raul do Couto. Concedida em 07/agosto de 2017, Belém/ PA.

IPPUR. 2017. Entrevista com Felisberto Demasceno. Concedida em 17/agosto, 2017, Brasília/DF.

IPPUR. 2018 (24 de abril). Depoimentos em Seminário Tucuruí: memórias de uma luta em curso. Auditório de Geociências, UFF. Belém/PA.

Manual. 1986. Estudos dos Efeitos Ambientais dos Sistemas Elétricos.

Nota. (1982, 8 de setembro). Nota de Esclarecimentos e Reivindicações das Famílias Atingidas pela Represa de Tucuruí a população. Tucuruí.

Ofício. (1985, 2 de fevereiro). Ofício do STR Jacundá e Tucuruí. Comissão dos Expropriados à Eletronorte. Tucuruí.

Relatório. 1987. Plano Diretor para a Melhoria do Meio Ambiente nas Obras e Serviços do Setor Elétrico v. I. Eletrobrás/ COMASE/ MINFRA.

Relatório. 1991/1993. Plano Diretor do Meio Ambiente do Setor Elétrico v. II. Eletrobrás/ COMASE/MINFRA.

Relatório. 1987. Relato de Comissão Técnica de Barragens e Meio Ambiente. Grupo de Trabalho: Comitê Brasileiro de Grandes Barragens.

Relatório. (1979, julho). Relatório da II Assembleia de Lavradores. Tucuruí.

Relatório. 1983. “Tucuruí - 10 anos depois”. História da Energia, Eletronorte.

Relatório. 1989. Usina Hidrelétrica Tucuruí: Memória Técnica. Coordenadoria Técnica do Projeto Memória - Eletronorte do Ministério de Minas e Gerais e Centrais Elétricas Brasileiras S.A. Eletrobras/ Eletronorte. Brasília.

Relatório. 1987 (8 de agosto). Relatório do Comitê Brasileiro de Grandes Barragens: Comissão técnica de barragens e Meio Ambiente. Brasília.

Relatório. 1989 (2 de janeiro). Relatório Interno da Eletronorte. Brasília.

\section{Outras referências}

Acselrad, Henri, e Maria das Graças da Silva. 2004. "Conflito social e mudança ambiental na barragem de Tucuruí". In Conflitos ambientais no Brasil, org. Henri Acselrad, 175-93. Rio de Janeiro: Relume Dumará.

Acselrad, Henri, e Maria das Graças da Silva. 2011. "Rearticulações sociais da terra e do trabalho em áreas de grandes projetos hidrelétricos na Amazônia - o caso de Tucuruí". In As tensões do lugar: hidrelétricas, sujeitos e licenciamento ambiental, org. Andréa Zhouri, 61-92. Belo Horizonte: EdUFMG.

Acselrad, Henri. 1991. "Planejamento autoritário e desordem socioambiental na Amazônia: crônica do deslocamento de populações de Tucuruí". Revista de Administração Pública 25 (4): 53-68.

Acselrad, Henri. 2010. "Mercado de terras e meio ambiente em áreas de grandes projetos de investimento - o caso da Usina Hidrelétrica de Tucuruí". Estudos Sociedade e Agricultura 18 (1): 158-92.

Bourdieu, Pierre. 1998. "O capital social - notas provisórias". In Escritos de educação, org. Maria Alice Nogueira, e Afrânio Catani, 65-9. Petrópolis: Vozes.

Bourdieu, Pierre. 2011. "O campo político”. Revista Brasileira de Ciência Política 5 (janei- 
Rodica Weitzman

ro-julho): 193-216.

Bronz, Deborah, e Marcos Otavio Bezerra. 2014. “'Grandes empreendimentos', administração pública e populações". Revista Antropolítica 37: 131-6.

Bronz, Deborah. 2013. "O Estado não sou eu”. Estratégias empresariais no licenciamento ambiental de grandes empreendimentos industriais. Dossiê Antropologia e Desenvolvimento. Campos 14 (1-2): 37-55.

Bronz, Deborah. 2016. Nos bastidores do licenciamento ambiental: uma etnografia das práticas empresariais em grandes empreendimentos. Rio de Janeiro: Contra Capa.

Buttel, Frederick H. 1992. "A sociologia e o meio ambiente: um caminho tortuoso rumo à ecologia humana". Perspectivas (15): 69-94.

Castro, Eduardo Viveiros, e Lucia M. M. de Andrade. 1988. "Hidrelétricas do Xingu: O Estado contra as sociedades indígenas". In As Hidrelétricas do Xingu e os Povos Indígenas, org. Leinad Ayer de O. Santos, e Lucia M. M. Andrade, 7-23. São Paulo: Comissão Pró-índio de São Paulo.

Cunha, Olivia Maria Gomes da, Castro, Celso. 2005. "Quando o campo é o arquivo". Estudos Históricos 36 (jul.-dez.): 3-5.

Cunha, Olivia Maria Gomes da. 2004. "Tempo imperfeito: uma etnografia do arquivo". Mana 10 (2): 287-322.

Des Chenes, Mary. Locating the past. 1997. In Anthropological locations: boundaries and grounds of a field science, eds. Akhil Gupta, e James Ferguson, 66-85. Berkeley: University of California Press.

Dias, Devanir Vieira, Antonio Del Maestro Filho, e Lúcio Flávio Renault de Moraes. 2003. "O paradigma weberiano da ação social: um ensaio sobre a compreensão do sentido, a criação de tipos ideais e suas aplicações na teoria organizacional". Revista de Administração Contemporânea 7 (2): 57-71.

Durkheim, Émile. 1995 [1912]. The elementary forms of the religious life. Traduzido por Karen E. Fields. New York: The Free Press.

Eagleton, Terry. 1997. Ideologia: uma introdução. São Paulo: EdUnesp.

Ewald, François. 1993. Foucault, a norma e o direito. Traduzido por António Fernando Cascais. Lisboa: veja.

Faillace, Sandra Tosta. 1990. Comunidade, etnia e religião: um estudo de caso na Barragem de Itá (RS/SC). Rio de Janeiro: Editora da UFRJ.

Fearnside, Philip M. 2015. Hidrelétricas na Amazônia: impactos ambientais e sociais na tomada de decisões sobre grandes obras. Manaus: Editora do INPA.

Foucault, Michel. 1971. A ordem do discurso. http://www.filoesco.unb.br/foucault.

Foucault, Michel. 1986. A arqueologia do saber. Rio de Janeiro: Forense Universitária.

Foucault, Michel. 1991. Vigiar e punir. Nascimento da prisão, 8 ed. Petrópolis: Vozes.

Goffman, Erving. 1974. Frame analysis: an essay on the organization of experience. London: Harper and Row.

Goodland, Robert. 1978. Environmental Assessment of the Tucuruí Hydroproject, rio Tocantins Amazônia, Brazil. Brasília: Eletronorte S.A.

Guattari, Félix, e Sueli Rolnik. 2005. Micropolítica: cartografias do desejo, $7^{\mathrm{a}}$ ed. Petrópolis: Vozes.

Hull, Mathew. 2012. "Documents and Bureaucracy". The Annual Review of Anthropology, 
251-67. California: Stanford University Press.

Lopes, José Sérgio Leite. 2006. “Sobre processos de 'ambientalização' dos conflitos e sobre dilemas da participação”. Horizontes Antropológicos 12 (25): 31-64.

Magalhães, Sonia Barbosa. 1987. "Hidrelétricas e impacto ambiental”. Boletim da Associação Brasileira de Antropologia 3: 62-64.

Medeiros, Leonilde Servolo de. 2012. "Os movimentos sociais como campo de pesquisa nas ciências humanas". Revista Mundos do Trabalho 4 (7): 7-31.

Mitchell, Timothy. 1999. "State, economy, and the state effect”. In State/culture: state formation after de cultural turn, ed. Georges Steimentz, 76-96. New York: Cornell University Press.

Mougeot, Luc. 1988. "Planejamento hidroelétrico e reinstalação de populações na Amazônia: primeiras lições de Tucuruí, Pará”. In Fronteiras, org. Catharine Aubertin, 231-50. Brasília; Paris: Editora Universidade de Brasília; Orstom.

Nader, Laura. 1972. "Up the Anthropologist: Perspectives gained from Studying Up”. In Reinventing Anthropology, Dell Hymes, 284-311. New York: Pantheon Books.

Novaes, j. 2015. "Estratégias de resistência de povos e comunidades tradicionais à hidrelétrica de Tucuruí: trajetórias identitárias e processos de expropriação". In Povos Tradicionais em colisão com estratégias empresariais no Maranhão e Pará, orgs. Rosa Elizabeth Acevedo Marin, e Jurandir Santos de Novaes, 173-203. Manaus: UEA Edições.

Osborne, David, e Ted Gaebler. 1994. Reinventando o governo: como o espírito empreendedor está transformando o setor público. Brasília: MH Comunicação.

Ribeiro, Gustavo Lins. 1988. Developing the Moonland: The Yacyreta Hydroelectric High Dam and Economic Expansion in Argentina. New York: The City University of New York.

Riles, Annelise, ed. 2006. Documents: artifacts of modern knowledge. Michigan: University of Michigan Press.

Rocha, Maria Célia. 2002. "Uma abordagem sócio-histórica da política de remanejamento das populações afetadas pelas hidrelétricas de Tucuruí". Dissertação do mestrado profissional, Universidade Federal do Amazonas, Manaus.

Santos, Silvio Coelho. 1990. Domination and the Arts of Resistance: Hidden Transcripts. New Haven and London: Yale University Press.

Santos, Silvio Coelho. 1992. "Metodologia para o estudo de Projetos de Desenvolvimento e suas implicações políticas: o caso das hidrelétricas". In Desenvolvimento e Direitos Humanos: a responsabilidade do antropólogo, orgs. Antonio A. Arantes, Guillermo Ruben, e Guita Debert, 91-101. Campinas: Ed. Unicamp.

Santos, Silvio Coelho. 1996. "Notas sobre o deslocamento de populações indígenas em consequência da implantação de hidrelétricas na Amazônia”. In Energia na Amazônia, orgs. Sonia Barbosa Magalhães, Rosyan de Caldas Britto, Edna Ramos, 689-96. Belém: Museu Paraense Emílio Goeldi/Universidade Federal do Pará/Associação das Universidades Amazônicas.

Sigaud, Lygia, Ana Luiza Martins-Costa, e Ana Maria Daou. 1987. Expropriação do campesinato e concentração de terras em Sobradinho: uma contribuição à análise dos efeitos da política energética do estado. Ciências Sociais Hoje. São Paulo: Vértice; Anpocs.

Sigaud, Lygia, Luiz Pinguelli Rosa, e Otávio Mielnik. 1983. Impactos de grandes projetos 
Rodica Weitzman

hidrelétricos e nucleares: aspectos econômicos, tecnológicos, sociais e ambientais, coord. AIE/COPPE. Rio de Janeiro: Marco Zero.

Sigaud, Lygia. 1988a. Efeitos sociais de grandes projetos hidrelétricos: as barragens de Sobradinho e Machadinho. In Impactos de grandes projetos hidrelétricos e nucleares. Aspectos econômicos, tecnológicos, sociais e ambientais, eds. Luiz Pinguelli, et al., 83-166. Rio de Janeiro: Coppe/UFRJ.

Sigaud, Lygia. 1988b. Implicações sociais da política do Setor Elétrico. In As hidrelétricas do Xingu e os Povos Indígenas, org. Leinad Ayer de O. Santos, e Lucia M. M. Andrade, 103-10. São Paulo: Comissão Pró-Índio de São Paulo .

Sigaud, Lygia. 1992. O efeito das tecnologias sobre comunidades rurais: o caso das grandes barragens. Revista Brasileira das Ciências Sociais 18, ano 7.

Sigaud, Lygia. 1995. A dimensão social em uma abordagem antropológica. Crença, descrença e interesses. Por uma sociologia das condutas face ao deslocamento compulsório. In Estado, Energia Elétrica e Meio Ambiente: o Caso das Grandes Barragens, org. Luiz Pinguelli, 162-78. Rio de Janeiro: UFRJ/COPPE/PPGAS.

Vainer, Carlos Bernardo, e Frederico G. Araújo. 1990. “Implantação de grandes hidrelétricas: estratégias do Setor Elétrico das Populações Atingidas". Travessia Revista do Migrante 23 (6): 8-24.

Vainer, Carlos Bernardo. 1993. "Planejamento e questão ambiental: qual é o meio ambiente que queremos planejar?" In Anais do V Encontro Nacional da Anpur 2: 556-71. Belo Horizonte: ANPUR.

Vainer, Carlos Bernardo. 2008. Conceito de "atingido": uma revisão do debate e diretrizes. In Vidas alagadas: conflitos socioambientais, licenciamento e barragens, org. Franklin Daniel Rothman, 39-63. Viçosa: Editora da UFV. 